\title{
Short-term Pulsing Improves Postharvest Leaf Quality of Cut Oriental Lilies
}

\author{
Ria T. Leonard and \\ Terril A. Nell
}

AdDITIONAL INDEX wORDs. benzyladenine, Chrysal BVB, Chrysal SVB, cytokinine, Fascination, gibberellin, Lilium, senescence, thidiazuron, and vase life

\begin{abstract}
SumMary. Several pulse solutions were tested for their effectiveness in preventing leaf senescence on four cut oriental lily cultivars (Lilium sp. 'Acapulco', 'Kissproof', 'Noblesse' and 'Star Gazer'). Stems were pulsed 24 hours after harvest for 1 hour, stored in boxes in the dark for 5 days at $3{ }^{\circ} \mathrm{C}\left(37.4{ }^{\circ} \mathrm{F}\right)$ then evaluated in postharvest conditions. A new commercial product called Chrysal BVB, a proprietary mixture manufactured by Pokon \& Chrysal (Miami) containing cytokinine and gibberellic acids, was the most effective product tested. Chrysal BVB [ $\left.1 \mathrm{~mL} \cdot \mathrm{L}^{-1}(0.1 \%)\right]$ prevented leaf chlorosis and abscission on 'Acapulco' and 'Noblesse' and significantly reduced it by $82 \%$ on 'Star Gazer' and by $69 \%$ on 'Kissproof'. Stems pulsed in Fascination, a commercial mixture containing $\mathbf{1 . 8} \%$ gibberellins $\left(\mathrm{GA}_{4+7}\right)$ and $1.8 \%$ benzyladenine $\left[5.4 \mathrm{mg} \cdot \mathrm{L}^{-1}(\mathrm{ppm})\right.$ each], virtually prevented leaf chlorosis on 'Noblesse', reduced it by $\mathbf{5 0 \%}$ or more on 'Acapulco' and 'Star Gazer', and significantly delayed it 8 days on 'Kissproof'. A $10 \mu \mathrm{M}(2 \mathrm{ppm})$ pulse in thidiazuron, a substituted phenylurea with cytokinin-like properties, delayed leaf chlorosis on 'Star Gazer' but to a lesser extent compared to BVB and Fascination. Chrysal SVB, a propri-
\end{abstract}

Department of Environmental Horticulture, P.O. Box 110670, University of Florida, Gainesville, FL 32611.

Florida Agricultural Experiment Station Journal Series No. R-09711. This research was supported by the American Floral Endowment. We gratefully acknowl edge flower donations from Sun Valley Floral Farms (Arcata, Calif.) and chemical donations from Pokon \& Chrysal (Miami), Valent USA Corp. (Walnut Creek, Calif.), and Aventis CropScience USA LP (Research Triangle Park, N.C.). Mention of a proprietary product or vendor does not constitute a guarantee or warranty of the product by the U.S. Dept. of Agriculture and does not imply its approval to the exclusion of other products or vendors that also may be suitable. 
etary mixture manufactured by Pokon \& Chrysal containing gibberellic acid, had no effect on reducing leaf chlorosis on 'Star Gazer'. None of the pulse solutions had adverse effects on bud opening, flower quality or vase life. Maintaining stems in a bulb flower preservative significantly reduced leaf chlorosis and abscission in all cultivars when stems were not pretreated with a pulse solution or when a pulse solution was ineffective.

A siatic and oriental hybrid lily (Lilium sp.) leaves become chlorotic and/or necrotic during storage, transport and consumer conditions and usually senesce or abscise before flowers. Long-term dark storage of lilies at low temperatures is one of the major factors that induce leaf disorders in both potted (Ranwala and Miller, 1998; Ranwala et al., 2000) and cut lilies (Han, 2001). Leaf chlorosis usually starts on the lower leaves and continues upward, greatly reducing quality and appearance. These symptoms can be present when removed from storage, but will often manifest themselves after plants have been maintained in an interior environment. The susceptibility to leaf disorders and the expressed symptoms (chlorosis, necrosis, and/or abscission) has been found to be cultivar dependent (Leonard et al., 1998).

The application of gibberellins (GA) and cytokinins as dips, sprays or in solution has proved beneficial in preventing leaf yellowing in alstroemeria (Alstroemeria) (Hicklenton, 1991), narcissus (Narcissustazetta) (Ichimura and Goto, 2000), goldenrod (Solidago canadensis) (Philosoph-Hadas et al., 1996) and calla lily (Zantedeschia aethiopica) (Skutnik et al., 2001). Similarly, foliar sprays of gibberellins and cytokinins have prevented or reduced leaf chlorosis and senescence in potted oriental hybrid lilies (Ranwala and Miller, 1998; Ranwala and Miller, 2000; Celikel et al., 2002) and easter lilies (Lilium longiflorum) (Han, 1997; Ranwala et al., 2000; Whitman et al., 2001). Recently, the use of gibberellin and benzyladenine (BA) on cut lilies has been investigated by Han (2001), who found a continuous application of $\mathrm{BA}+\mathrm{GA}_{4+7}\left(0.5\right.$ or $2.5 \mathrm{mg} \cdot \mathrm{L}^{-1}$ of each) via a preservative solution or a 4-h pulse $\left(25 \mathrm{mg} \cdot \mathrm{L}^{-1}\right.$ each of BA and $\left.\mathrm{GA}_{4+7}\right)$, prevented leaf chlorosis in cut asiatic and oriental lilies, but increased bud blasting. Due to the detrimental effect on buds when in solution, Han (2001) concluded that cut lilies can be sprayed with $25 \mathrm{mg} \cdot \mathrm{L}^{-1}$ each of BA and $\mathrm{GA}_{4+7}$ prior to or after cold storage to prevent leaf chlorosis and improve postharvest quality.

New product formulations and the continued testing of new compounds to prevent leaf senescence on many species of cut flowers continue to be pursued by researchers and the cut flower industry. More recently, thidiazuron (TDZ), a substituted phenylurea compound with cytokininlike properties currently registered for use as an herbicide and defoliant, was found to markedly extend leaf longevity of alstroemeria (Ferrante et al., 2002).

The objective of this work was to test the effects of several relatively new compounds on leaf senescence, bud opening and vase life of cut oriental lilies.

\section{Material and methods}

Four cultivars of cut oriental lilies, 'Acapulco', 'Kissproof', 'Noblesse' and 'Star Gazer', were obtained from Sun Valley Floral Farms, Arcata, Calif. Stems were harvested on 12 June 2002 at commercial maturity (buds well colored but not open) and hydrated in water for 2 h at $5^{\circ} \mathrm{C}\left(41.0^{\circ} \mathrm{F}\right)$. It took 14-16 weeks to force these varieties to achieve marketable stage. Stems were then sleeved, boxed, and transported to the University of Florida (UF), Gainesville, within $24 \mathrm{~h}$.

Pulse treatments. Upon arrival at the UF laboratory, stems were maintained in commercial bunches (eight stems/bunch) with plastic sleeves, cut dry and placed in three different solutions for $1 \mathrm{~h}$. This short-term treatment of the flowers in solutions after harvest is referred to as a pulse or pulsing treatment. The pulse solutions used included a new commercial product called Chrysal BVB $\left(1 \mathrm{~mL} \cdot \mathrm{L}^{-1}\right)$, which is a proprietary mixture of cytokinine and gibberellic acids (Pokon \& Chrysal, Naarden, The Netherlands), Fascination $\left(5.4 \mathrm{mg} \cdot \mathrm{L}^{-1}\right.$ each of BA and $\left.\mathrm{GA}_{4+7}\right)$, a commercial mixture of $1.8 \% \mathrm{BA}$ and $1.8 \% \mathrm{GA}_{4+7}$ (Valent BioSciences Corp., Libertyville, Ill.) or tap water (control). These rates were chosen following the manufacturers recommended rates. Each pulse treatment was mixed with warm tap water and the flowers were kept at $21.1^{\circ} \mathrm{C}\left(70^{\circ} \mathrm{F}\right)$ at a light level of $10 \mu \mathrm{mol} \cdot \mathrm{m}^{-2} \cdot \mathrm{s}^{-1}$ during the 1 -h pulse treatment. After treatment, the sleeved bunches were placed in boxes and stored dry in darkness at $3{ }^{\circ} \mathrm{C}(37.4$ $\left.{ }^{\circ} \mathrm{F}\right)$ for $5 \mathrm{~d}$.

After storage, sleeves were removed and stems were cut dry and placed in buckets containing tap water for $2 \mathrm{~d}$ at $20.0^{\circ} \mathrm{C}\left(68^{\circ} \mathrm{F}\right)$ and $10 \mu \mathrm{mol}$. $\mathrm{m}^{-2} \cdot \mathrm{s}^{-1}\left(12 \mathrm{~h} \cdot \mathrm{d}^{-1}\right)$ from cool-white fluorescent lamps for retail simulation. After retail simulation, stems were recut to $40 \mathrm{~cm}$ ( 15.7 inches) and the lower leaves were removed to avoid submersion in the vase solution. Stems were placed in vases containing tap water and placed in postharvest conditions maintained at $21.1^{\circ} \mathrm{C}$ and $10 \mu \mathrm{mol} \mathrm{m} \mathrm{m}^{-2} \mathrm{~s}^{-1}$ $\left(12 \mathrm{~h} \cdot \mathrm{d}^{-1}\right)$ from cool-white fluorescent lamps. The number of chlorotic and abscised leaves was recorded every 2 $\mathrm{d}$ in postharvest conditions. A leaf was considered chlorotic when $\geq 30 \%$ of the leaf area became yellow or brown. The number of buds that developed into flowers was recorded. Vase life was calculated from the time stems were placed into vases until the last flower on the stem senesced.

Leaf readings were obtained using a Minolta SPAD-502 (Specialty Products Agricultural Division) Chlorophyll Meter (Spectrum Technologies, Plainfield, Ill). The values determined by this meter, referred to as the SPAD value, are calculated based on the amount of light transmitted through the leaf in two wavelength regions (650 and $940 \mathrm{~nm}$ ). This measure indicates how green a leaf is, which is related to the relative amount of chlorophyll present. The third leaf below the bottom flower was repeatedly measured after 0 (initial), 4, 7, and $12 \mathrm{~d}$ in postharvest conditions.

A total of four replications was used, with one vase per replication. Each vase contained three stems. A total of 12 stems per treatment was evaluated using a randomized complete-block design.

VASE PRESERVATIVE SOLUTION. The methods and procedures outlined above also apply to this experiment except stems did not receive any pulse treatment. Stems were hydrated in tap water for $\mathrm{l} \mathrm{h}$ upon arrival at UF, then boxed and placed in storage conditions as outlined above. After retail simulation, stems were maintained in vase solutions of tap water or Chrysal Clear Bulb Flowers floral preservative [10 $\mathrm{g} \cdot \mathrm{L}^{-1}(1.3 \mathrm{oz} / \mathrm{gal})$ tap water; Pokon \& 
Chrysal, Naarden, The Netherlands).

COMBINED PULSE AND VASE PRESERVATIVE SOLUTIONS. Handling methods, storage, retail, and postharvest conditions were identical as described above. The cultivar tested was 'Star Gazer', which was harvested on 24 Apr. 2002 at the same farm and developmental stage listed above. Stems were pulsed for $1 \mathrm{~h}$ in the following solutions upon arrival at the UF laboratory: Chrysal BVB [2 $\mathrm{mL} \cdot \mathrm{L}^{-1}(0.2 \%)$ water], Fascination $\left(5.4 \mathrm{mg} \cdot \mathrm{L}^{-1}\right.$ each of $1.8 \% \mathrm{BA}$ and $\left.1.8 \% \mathrm{GA}_{4+7}\right)$, thidiazuron (TDZ) at $10 \mu \mathrm{M}$ (Aventis CropScience USA LP, Research Triangle Park, N.C.) and tap water (control). Stems were also pulsed in the commercial product called Chrysal SVB, a proprietary mixture of gibberellic acid (Pokon \& Chrysal) using the manufacturers recommended rate of one tablet per $3 \mathrm{~L}(3.2 \mathrm{qt})$ water. The vase solutions during the postharvest evaluations included tap water or Chrysal Clear Bulb Flowers floral preservative (10 g. $\cdot \mathrm{L}^{-1}$ tap water; Pokon \& Chrysal).

Analysis of variance was performed using the Statistical Analysis System GLM procedure (SAS Institute, Cary, N.C.). Percentage data were arcsin transformed before analysis but the true means are reported. When treatment effects were significant $(P \leq 0.05)$, Duncan's multiple range test was used to determine differences among the means.

\section{Results}

Pulse treatments. Leaf chlorosis and abscission was significantly $(P$ $\leq 0.05$ ) reduced and/or eliminated when stems were pulsed with BVB or Fascination compared to water (Fig. 1). At the concentration tested, BVB was more effective than Fascination for all cultivars, except 'Noblesse', where both chemicals were equally effective. BVB prevented chlorotic leaves on 'Acapulco' and 'Noblesse' and significantly reduced it by $82 \%$ on 'Star Gazer' and by $69 \%$ on 'Kissproof', cultivars extremely sensitive to early leaf senescence. Fascination reduced leaf yellowing by $~ 50 \%$ in 'Acapulco' and 'Star Gazer' after $12 \mathrm{~d}$ in postharvest conditions, while it was no longer effective on 'Kissproof' after this time period. Fascination, however, was effective in delaying the onset of leaf senescence in 'Kissproof' compared to control plants.

After $4 \mathrm{~d}$ in postharvest condi-
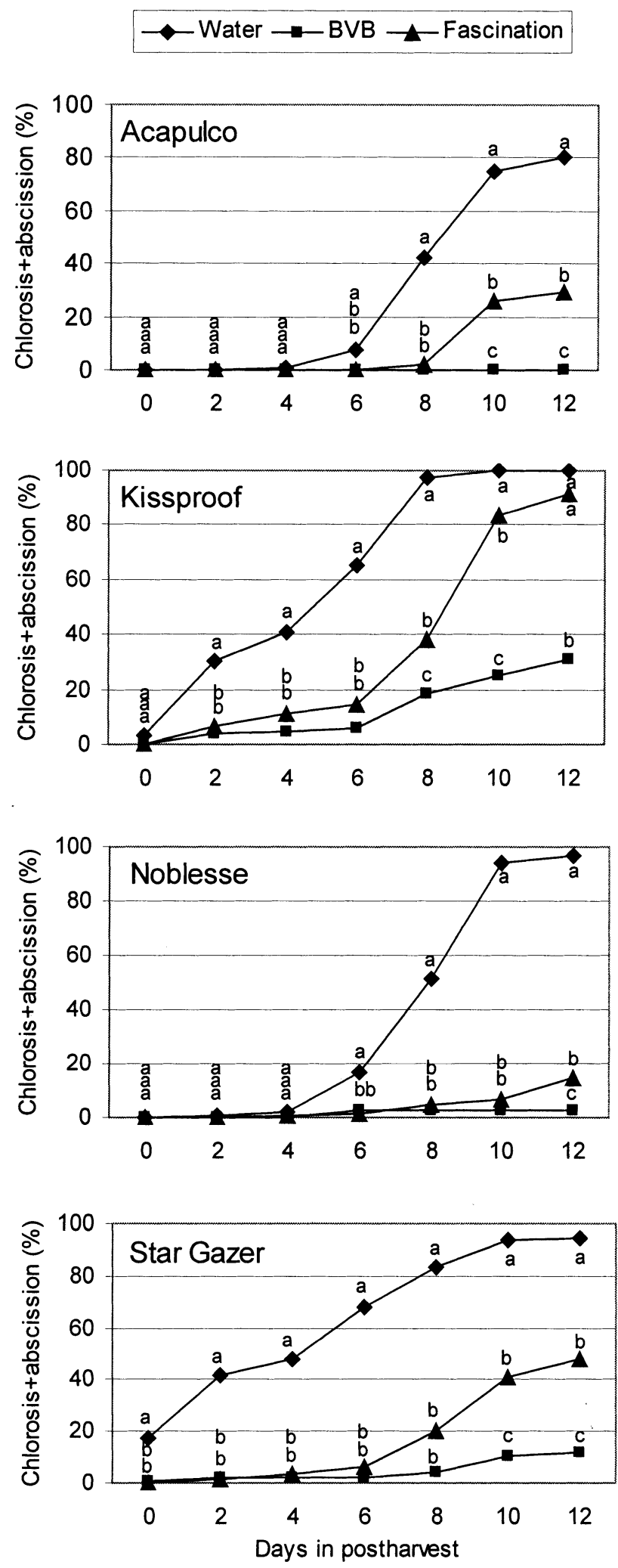

Fig. 1. Percent leaf chlorosis and abscission of cut oriental lily cultivars Acapulco, Kissproof, Noblesse, and Star Gazer over time in postharvest conditions. Stems were pulsed 24 $\mathrm{h}$ after harvest for $1 \mathrm{~h}$ in Chrysal BVB $\left[1 \mathrm{~mL} \cdot \mathrm{L}^{-1}(0.1 \%)\right]$, Fascination $\left[5.4 \mathrm{mg} \cdot \mathrm{L}^{-1}(\mathrm{ppm})\right.$ each of $1.8 \%$ benzyladenine and $1.8 \%$ gibberellins $\left.\left(\mathrm{GA}_{4+7}\right)\right]$ or water (control). For each cultivar, means within each time point with different letters are significantly different at $P \leq 0.05$ using Duncan's multiple range test. 
tions, leaf SPAD values were significantly lower $(P \leq 0.05)$ in stems pulsed in water compared to those pulsed with BVB and Fascination (Fig. 2). Data were pooled over cultivar since no significant differences in the leaf SPAD value were observed among cultivars. Compared to initial readings, the leaf SPAD value remained unchanged on BVB treated stems while it deceased by $67 \%$ on water controls and by $40 \%$ on stems pulsed in Fascination after $12 \mathrm{~d}$ in postharvest conditions. Leaf SPAD values on stems pulsed in Fascination were significantly higher $(P \leq 0.05)$ compared to stems pulsed in water and were similar to BVB treated stems up to day 7.

The pulse treatments did not affect bud opening $(P \leq 0.05)$ in any of the cultivars evaluated (data not shown). Depending on cultivar, vase life was either not affected or increased when stems were treated with pulsing solutions (Fig. 3). Stems pulsed with BVB had a significant $(P \leq 0.05)$ increase in longevity of 2 and $3 \mathrm{~d}$ for 'Acapulco' and 'Noblesse', respectively, compared to control plants, while no differences were observed in 'Kissproof' or 'Star Gazer'. Fascination increased vase life of 'Noblesse' by $2 \mathrm{~d}$ compared to control plants, while no significant increases were observed in the other cultivars treated with Fascination.

VASE PRESERVATIVE SOLUTION. Maintaining stems in the floral preservative solution significantly reduced leaf chlorosis and abscission on all cultivars compared to water when no pulse treatment was used (Fig. 4). The amount of reduction and the number of days the onset of leaf senescence was delayed was cultivar dependent. 'Star Gazer' and 'Kissproof' were extremely sensitive to early leaf senescence and although the preservative reduced leaf chlorosis on these cultivars, it was not as effective compared to the reduction in leaf chlorosis observed on 'Acapulco' and 'Noblesse'. While leaf chlorosis was below $20 \%$ after 12 d for 'Acapulco' and 'Noblesse' maintained in the floral preservative, it reached nearly $40 \%$ or higher in 'Star Gazer' and 'Kissproof' within $6 \mathrm{~d}$.

The floral preservative was effective in maintaining the leaf SPAD value over time in postharvest conditions, in contrast to the decline observed when stems were maintained in water. After $12 \mathrm{~d}$ in postharvest conditions, there was a $70 \%$ reduction in the leaf SPAD

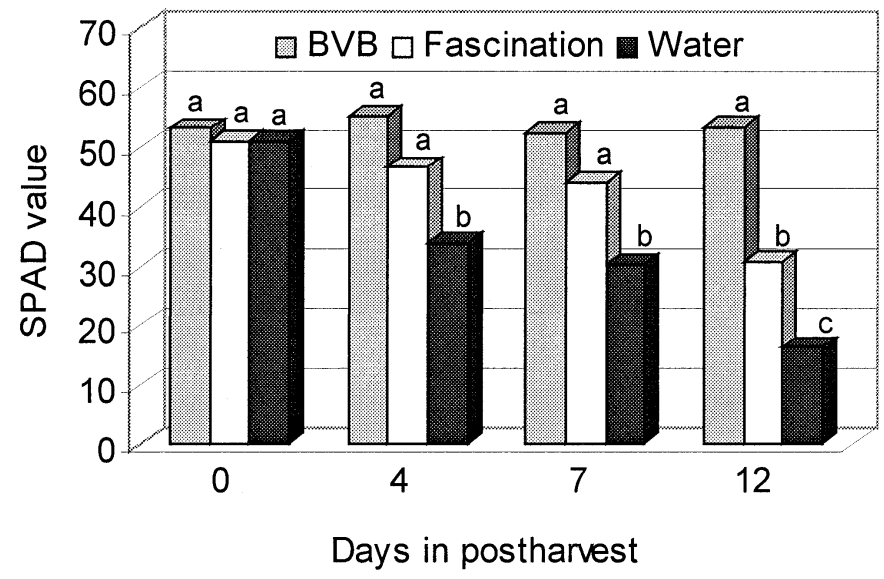

Fig. 2. Leaf SPAD values in cut oriental lilies over time in postharvest conditions measured with a Minolta SPAD-502 (Specialty Products Agricultural Division) chlorophyll meter. Stems were pulsed $24 \mathrm{~h}$ after harvest for $1 \mathrm{~h}$ in Chrysal BVB $\left[1 \mathrm{~mL} \cdot \mathrm{L}^{-1}(0.1 \%)\right]$, Fascination $\left[5.4 \mathrm{mg} \cdot \mathrm{L}^{-1}(\mathrm{ppm})\right.$ each of $1.8 \%$ benzyladenine and $1.8 \%$ gibberellins $\left.\left(\mathrm{GA}_{4+7}\right)\right]$ or in water (control). Means with different letters within each time point are significantly different at $P \leq 0.05$ using Duncan's multiple range test. Data pooled over cultivar.

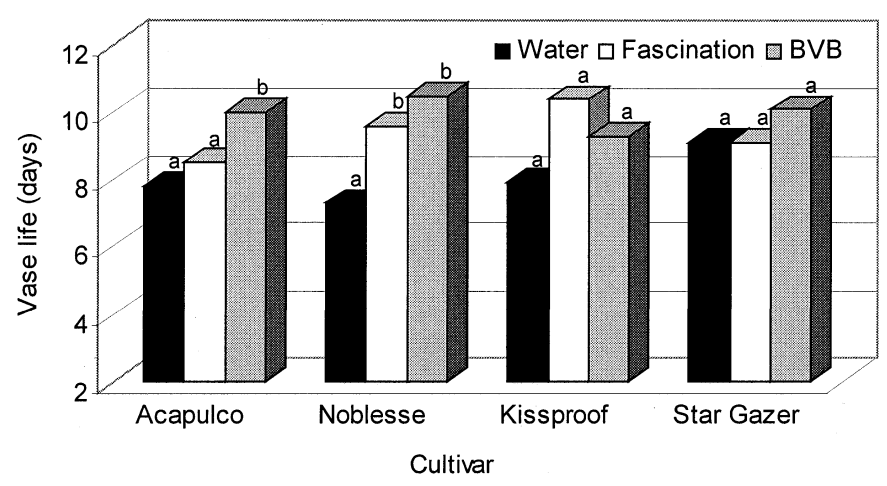

Fig. 3. Vase life of cut oriental lily cultivars Acapulco, Kissproof, Noblesse, and Star Gazer when pulsed $24 \mathrm{~h}$ after harvest for $1 \mathrm{~h}$ in Chrysal BVB $\left[1 \mathrm{~mL} \cdot \mathrm{L}^{-1}(0.1 \%)\right]$, Fascination $\left[5.4 \mathrm{mg} \cdot \mathrm{L}^{-1}(\mathrm{ppm})\right.$ each of $1.8 \%$ benzyladenine and $1.8 \%$ gibberellins $\left.\left(\mathrm{GA}_{4+7}\right)\right]$ or water (control). Means with different letters within each cultivar are significantly different at $P$ $\leq 0.05$ using Duncan's multiple range test.

value when stems were maintained in water compared to the preservative (data not shown).

No differences were observed in bud opening between vase solutions or among cultivars (data not shown). Significant differences $(P \leq 0.05)$ in vase life were observed between vase solutions. Stems maintained in water lasted $8.0 \mathrm{~d}$, while those maintained in preservative lasted $10.5 \mathrm{~d}$.

COMBINED PULSE AND VASE PRESERVATIVE SOLUTIONS. 'Star Gazer' stems pulsed in water and Chrysal SVB exhibited severe leaf chlorosis, however, this was significantly reduced when stems were maintained in the floral preservative solution compared to water (Fig. 5). TDZ delayed leaf chlorosis, but by the end of vase life, $80 \%$ of the leaves were chlorotic when maintained in water compared to $31 \%$ in preservative. BVB and Fascination were very effective in maintaining leaf quality in both vase solutions. The preservative significantly reduced leaf chlorosis in 'Star Gazer' when the pulse solutions were ineffective. The treatments had no effect on 'Star Gazer' bud opening, as $100 \%$ of the buds opened 

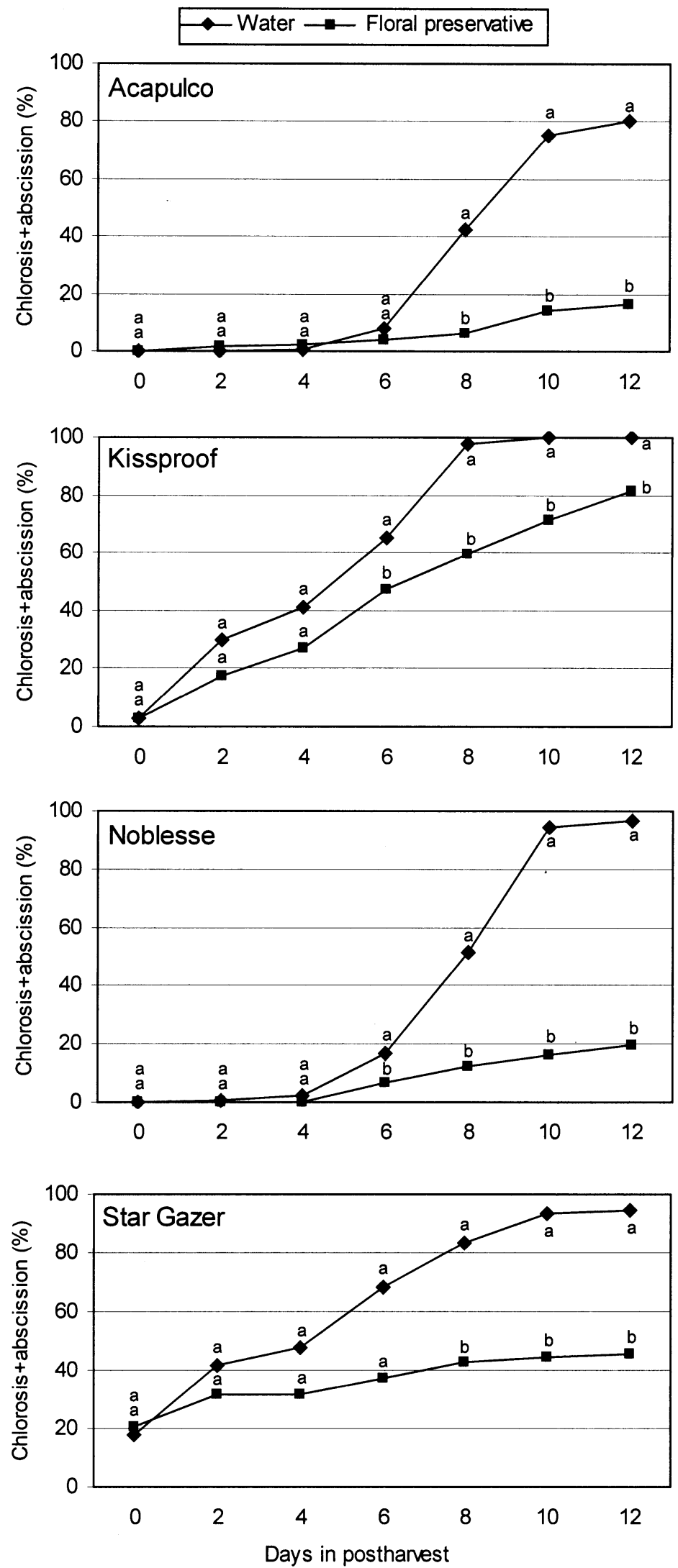

Fig. 4. Leaf chlorosis and abscission of cut oriental lily cultivars Acapulco, Kissproof, Noblesse, and Star Gazer when maintained in a vase solution of water or Chrysal Clear Bulb Flowers floral preservative with no prior pulsing treatment. For each cultivar, means within each time point with different letters are significantly different at $P \leq 0.05$ using Duncan's multiple range test. on all treatments, nor were there any differences in vase life, which averaged $7.2 \mathrm{~d}$ (data not shown).

\section{Discussion}

Postharvest leaf yellowing of cut lilies is a major problem since it occurs prior to flower senescence, thus detracting from the overall appearance and adversely affecting consumer satisfaction. All cut lily cultivars in this study suffered from leaf chlorosis during postharvest evaluations when no preventive treatments were applied. By the time flowers senesced, all nontreated stems had $80 \%$ to $100 \%$ chlorotic leaves. Our results demonstrate that pulsing cut oriental lilies after harvest with Chrysal BVB, Fascination or TDZ can delay or prevent leaf senescence in all of the cultivars tested, however, the magnitude and the duration of the response was dependent on both cultivar and pulse solution (Figs. 1 and 5 ). In addition, there were no detrimental effects on bud opening or vase life when stems were pulsed.

Our results show that pulsing stems in Chrysal BVB was the most effective treatment in preventing or significantly reducing leaf chlorosis in all cultivars. Fascination had an intermediate effect followed by TDZ. Pulsing stems in Chrysal SVB had no effect in reducing leaf senescence. Han (2001) reported that a 4 -h pulse in 25 $\mathrm{mg} \cdot \mathrm{L}^{-1}$ each of $\mathrm{BA}$ and $\mathrm{GA}_{4+7} \mathrm{com}-$ pletely eliminated the development of leaf yellowing in 'Star Gazer' lily, but induced blasting of all of the third buds on each stem. No bud blasting was observed in any of the treatments of this study. Perhaps the shorter pulse period of $\mathrm{l} \mathrm{h}$ and the lower concentration of $\mathrm{BA}$ and $\mathrm{GA}_{4+7}\left(5.4 \mathrm{mg} \cdot \mathrm{L}^{-1}\right.$ each) used in our study eliminated any adverse affects on bud development. Pulsing has proven beneficial for other cut flower species without any adverse effects to flowers or buds (Hicklenton, 1991; Ichimura and Goto, 2000; Philosoph-Hadas et al., 1996).

TDZ was found to be very effective in delaying leaf yellowing of alstroemeria that was pulsed for $24 \mathrm{~h}$ with a $10-\mu \mathrm{M}$ concentration with no effect on petal wilting (Ferrante et al., 2002). Although our results did show a delay in leaf yellowing of 'Star Gazer' when treated with TDZ, nearly $80 \%$ of the leaves were chlorotic at flower senescence compared to less than $10 \%$ for BVB and Fascination when 

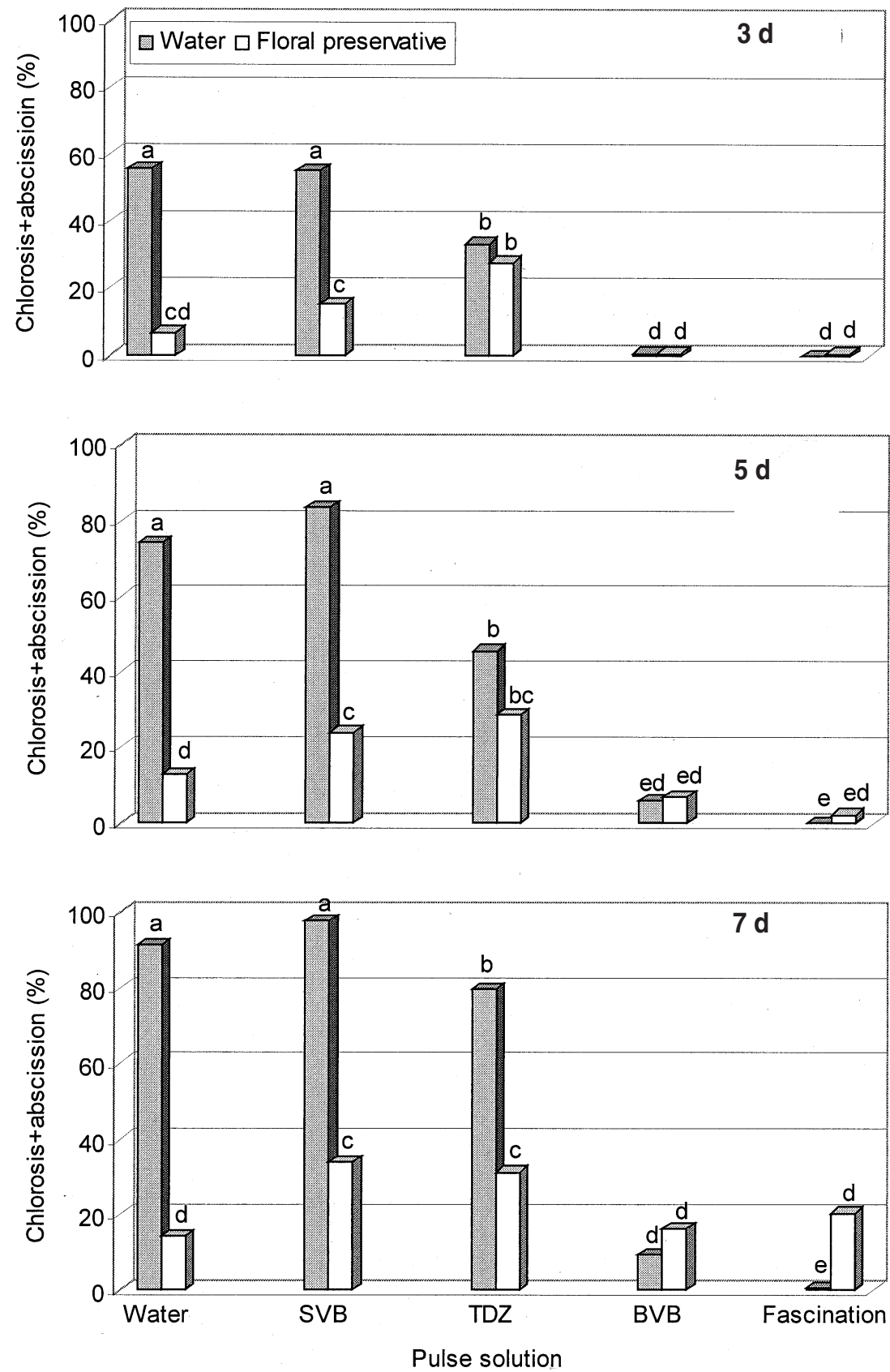

Fig. 5. Percent leaf chlorosis and abscission of cut 'Star Gazer' lily after 3, 5, and $7 \mathrm{~d}$ in postharvest conditions maintained in vase solutions of water or Chrysal Clear Bulb Flowers floral preservative after pulsing for $1 \mathrm{~h}$ with Chrysal SVB [one tablet per $3 \mathrm{~L}(3.2 \mathrm{qt})$ ], Chrysal BVB [2 mL. $\mathrm{L}^{-1}(0.2 \%)$, Fascination [5.4 $\mathrm{mg} \cdot \mathrm{L}^{-1}(\mathrm{ppm})$ each of $1.8 \%$ benzyladenine and $1.8 \%$ gibberellins $\left.\left(\mathrm{GA}_{4+7}\right)\right]$, thidiazuron [TDZ $(10 \mu \mathrm{M})]$, or water (control). Means with different letters within each time point are significantly different at $P \leq 0.05$ using Duncan's multiple range test.

maintained in water (Fig. 5). Perhaps TDZ would have been more effective in our study had the stems remained in the pulse solution for a longer period of time or if a higher concentration was used.

The type, onset, and rate of acceleration in which leaf chlorosis occurred varied greatly among the cultivars tested. It appears the more sensitive the cultivar was to early leaf senescence, the less reactive it was to the pulsing solution. For sensitive cultivars, a higher concentration or a longer pulse time may overcome this discrepancy in cultivar response. Differences in cultivar responses are not unusual as reported for cut lilies
(Han, 2001) and potted lilies (Celikel et al., 2002).

Maintaining stems in the preservative significantly reduced leaf damage when the pulse solution was ineffective or had moderate effects (Fig. 5). Continuous pulsing via vase solutions have shown excellent results in cut narcissus (Ichimura and Goto, 2000), chrysanthemum (Dendranthemagrandiflora) (Petridou et al., 2001) and alstroemeria (Ferrante et al., 2002). It is common practice in the United States to provide consumers with packets of floral preservatives with their floral purchases. The preservative used in this study was specially formulated for bulb flowers with the benefit of not only prolonging vase life but, as our results show, in significantly reducing leaf yellowing. Since leaf yellowing can occur prior to consumer purchases, pulsing after harvest by growers or wholesalers is the best strategy. Providing this bulb preservative to consumers is also recommended, especially if stems have not been pretreated.

It is clear that cut lilies need to be treated to improve the postharvest quality of the leaves until breeders can overcome this problem genetically. This study demonstrates that leaf senescence of cut oriental lilies can be easily prevented or reduced by pulsing with commercially formulated solutions or by maintaining stems in a specialty formulated bulb preservative with no adverse affects to bud development or vase life. Chrysal BVB was the most effective product tested, followed by Fascination and TDZ, while Chrysal SVB was found to be ineffective. Results did vary depending on cultivar, with the most sensitive cultivars being less but moderately responsive to the pulse solutions. By continued work with breeders in selecting cultivars less prone to leaf senescence and the establishment of preventive treatments, the postharvest quality problems of cut lilies can be easily reduced or eliminated.

\section{Literature cited}

Celikel, F., L. Dodge and M.S. Reid. 2002. Efficacy of 1-MCP (1-methylcyclopropene) and promalin for extending the post-harvest life of oriental lilies (Lilium $\mathrm{x}$ 'Mona Lisa' and 'Star Gazer'). Sci. Hort. 93:149-155.

Ferrante, A., D.A. Hunter, W.P. Hackett 
and M.S. Reid. 2002. Thidiazuron-A potent inhibitor of leaf senescence in Alstroemeria. Postharvest Biol. Technol. 25:333-338.

Han, S. 1997. Preventing postproduction leaf yellowing in easter lily. J. Amer. Soc. Hort. Sci. 122: 869-872.

Han, S. 2001. Benzyladenine and gibberellins improve postharvest quality of cut asiatic and oriental lilies. HortScience 36:741-745.

Hicklenton, P.R. 1991. GA $\mathrm{GA}_{3}$ and benzylaminopurine delay leaf yellowing in cut Alstroemeria stems. HortScience 26:1198-1199.

Ichimura, K. and R. Goto. 2000. Effect of gibberellin $\mathrm{A}_{3}$ on leafyellowing and vase life of cut Narcissus tazetta var. chinensis flowers. J. Jpn. Soc. Hort. Sci. 69:423-427.

Leonard, R.T., T.A. Nell, A.A. De Hertogh, and L. Gallitano. 1998. Lilies your customers will love. GrowerTalks 62:80-89.

Petridou, M., C. Voyiatzi, and D. Voyiatzis. 2001. Methanol, ethanol and other compounds retard leaf senescence and improve vase life and quality of cut chrysanthemum flowers. Postharvest Biol. Technol. 23:79-83.

Philosoph-Hadas, S., R. Michaeli, Y. Reuveni, and S. Meir. 1996. Benzyladenine pulsing retards leaf yellowing and improves quality of goldenrod (Solidago canadensis) cut flowers. Postharvest Biol. Technol. 9:65-73.

Ranwala, A.P. and W.B. Miller. 1998. Gibberellin $_{4+7}$, benzyladenine, and supplemental light improve postharvest leaf and flower quality of cold-stored 'Star Gazer' hybrid lilies. J. Amer. Soc. Hort. Sci. 123:563-568.

Ranwala, A.P. and W.B. Miller. 2000. Preventive mechanisms of gibberellin and light on low-temperature-induced leaf senescence of Lilium cv. Star Gazer. Postharvest Biol. Technol. 19:85-92.

Ranwala, A.P., W.B. Miller, T.I. Kirk, and P.A. Hammer. 2000. Ancymidol drenches, reversed greenhouse temperatures, postgreenhouse cold storage, and hormone sprays affect postharvest leaf chlorosis in easter lily. J. Amer. Soc. Hort. Sci. 125:248-253.

Skutnik, E., A. Lukaszewska, M. Serek, and J. Rabiza. 2001. Effect of growth regulators on postharvest characteristics of Zantedeschia aethiopica. Postharvest Biol. Technol. 21:241-246.

Whitman, C.A., R.D. Heins, R. Moe, and K. Funnell. 2001. GA ${ }_{4+7}$ plus benzyladenine reduce foliar chlorosis of Lilium longiflorum. Sci. Hort. 89:143-154. 